\title{
As Relações de Gênero e as Percepções dos/das Motoristas no Âmbito do Sistema de Trânsito
}

\section{Relations of gender and perceptions}

of drivers in the ambit of the traffic system

Nemésio Dario

Vieira de Almeida

Ana Karina B. de Lima

Consuelo M.

Albuquerque

Luciana Antunes

Universidade Católica de Pernambuco

UNICAP

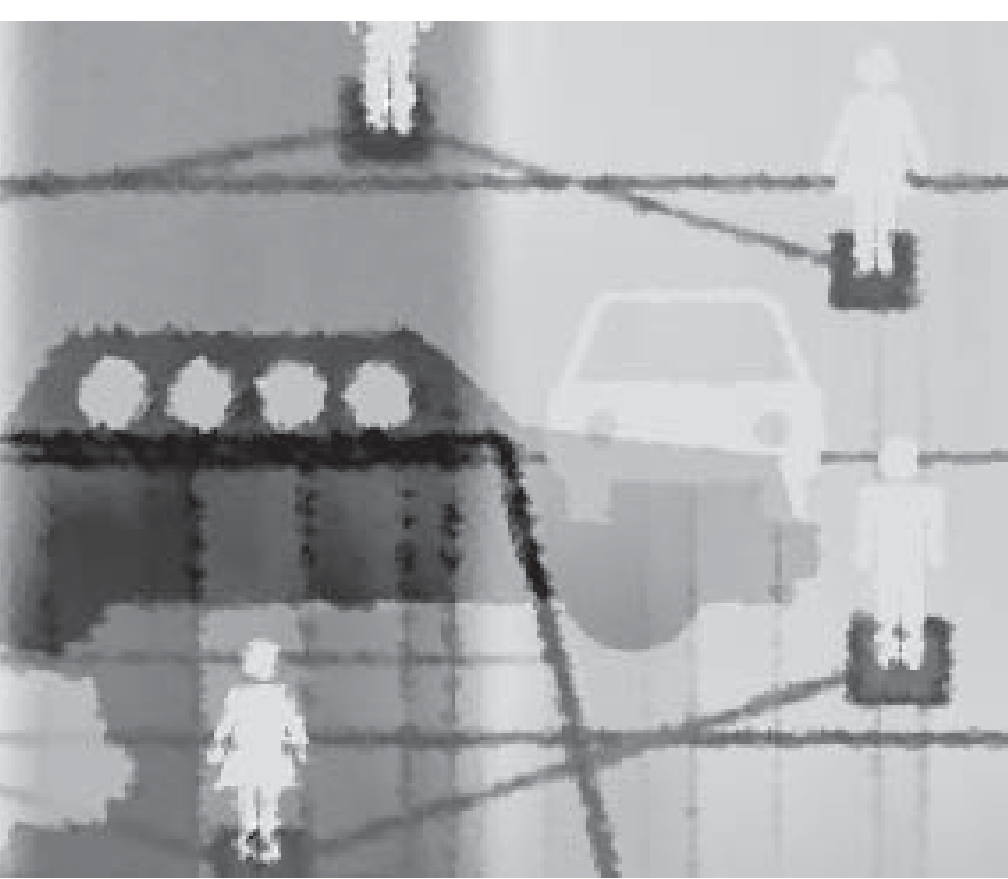




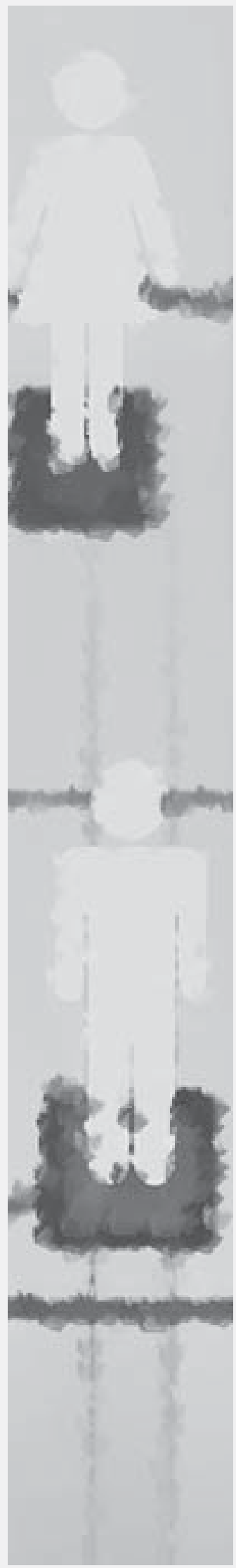

Resumo: Este artigo teve o propósito de estudar não só as relações de gênero no âmbito do sistema de trânsito, pesquisando como a mulher motorista e o homem motorista percebem e compreendem a si mesmo e ao outro sexo, bem como o de investigar as representações sociais existentes. Participaram da pesquisa 84 motoristas, com faixa etária de 18 a 60 anos de idade, sendo 42 do sexo feminino e 42 do sexo masculino. A coleta dos dados foi realizada através de contatos com homens e mulheres em universidades, locais de trabalho e em domicílio, na cidade do Recife, por meio de uma entrevista com duas perguntas e um questionário constituído por quatro questões abertas que, posteriormente, foram reunidas e organizadas segundo os dados obtidos. Inicialmente, foram levantadas e registradas todas as respostas obtidas para cada questão, sendo que cada uma constituiu uma temática de análise. A seguir, foi realizada uma nova leitura do material. Buscava-se aquilo que era essencial em cada resposta. Verificou-se a natureza das categorias emergentes e sua freqüência em cada tema. Cabe salientar que uma resposta possuía mais de uma categoria, por isso, o número de respostas não corresponde ao número de sujeitos. Concluímos que: (a) os papéis culturais influíram na percepção que o/a motorista possui de si mesma/o e a respeito da pessoa do outro sexo; (b) observou-se, também, diferença marcante de gênero na maneira como as pessoas encaram as relações no trânsito.

Palavras-chave: gênero, representação social, trânsito.

Abstract:This article has the aim of studing the relations of gender in the ambit of the traffic system, searching as the woman driver and the man driver perceive and understand themselves and the other sex as well as his/her own to investigate the existing social representations. 84 drivers, from 18 to 60 years old, participated in the research, 42 female sex and 42 male. The collection of the data was carried through contacts with men and women in the university, workstations and the domicile in the city of Recife by means of an interview with two questions and a questionnaire with four open questions, that later congregated and organized the data. Initially, all the answers were raised and registered; each one constituted a topic of analysis. To follow, a new reading of the material was carried through. It was searched what was essential in each reply. It was verified the nature of the emergent categories and its frequency in each subject. It should be pointed out that each reply had more than a category, therefore the number of answers does not correspond to the number of citizens. We concluded that: (a) the cultural papers had influenced the perception's drivers about themselves and the person of the other sex; (b) difference of gender was also observed in the way people face the relations in the traffic.

Key words: gender, social representation, traffic.

"O indivíduo

histórico-social, que é também um ser biológico, se constitui atrovés da rede de interrelações sociais".

Marlene Neves Strey 
O tema das crenças e atitudes das mulheres e homens sobre o comportamento que experimentam no âmbito do sistema de trânsito começa a ter uma dimensão mais ampla no campo de estudo da Psicologia social. O presente artigo se propõe a refletir sobre as diferentes percepções dos/das motoristas dentro da perspectiva dos estudos de gênero.

A concepção de gênero é formulada como distinção ao de sexo. Sexo refere-se, exclusivamente, ao aspecto biológico e anatômico, que determina se o ser humano é um homem ou uma mulher e, em caso mais raro, hermafrodita (Strey, 1994). Gênero indica uma construção psicossocial, cultural e historicamente construída ao longo do desenvolvimento, que vai definir os papéis masculino e feminino, significando e caracterizando a personalidade, o comportamento sexual, a aparência física, etc., tanto do homem como da mulher em uma dada sociedade (Scott, 1995; Strey, 1994).

De acordo com o Conselho Federal de Psicologia (2000), as discussões atuais sinalizam a urgente necessidade de a Psicologia responder à problemática gerada pelo fenômeno trânsito. Enquanto fenômeno que se dá nas vias públicas e envolve o ir e vir de pessoas (pedestre, motorista, ciclista e motociclista), não pode ser entendido apenas como um campo disciplinar voltado para o indivíduo em suas ações no trânsito.

Segundo dados do Departamento Estadual de Trânsito de Pernambuco - DETRAN-PE (2002), o Estado tem um total de 890.415 motoristas habilitados, sendo 20,76\% de mulheres, ou seja, 184.850 motoristas mulheres; elas são minoria na direção, mas são também minoria, proporcionalmente, nas infrações de trânsito.

O tema dos papéis de gênero em nossa sociedade ocidental industrializada está diretamente vinculada à socialização de gênero e às crenças e atitudes sobre as relações no trânsito, já que o gênero atua como determinante fundamental do status na hierarquia social, levando a certas formas de viver de homens e mulheres e os papéis que cada um deve assumir em função das demandas sociais (Almeida, N.D.V., 2002e).

Assim, contextualizar o fenômeno gênero no âmbito do sistema de trânsito num tempo e num espaço requer um olhar que permita conhecer e avaliar a dimensão das mudanças e transformações sociais vividas num momento histórico bem como a construção de novos padrões de conduta normativos.

\section{Método}

Participantes

Com o objetivo de fazer reflexões acerca das relações dos/das motoristas no espaço de trânsito dentro de uma perspectiva de gênero, visando a caracterizá-lo e identificar qual a percepção e compreensão que o/a motorista tem de si mesmo e do outro sexo, bem como o de investigar as representações sociais, participaram desta pesquisa 84 sujeitos, todos/as motoristas devidamente habilitados, sendo 42 do sexo feminino e 42 do sexo masculino, com idades entre 18 e 60 anos, residentes na cidade do Recife. Foram realizados 72 questionários e 12 entrevistas, analisados através do método de análise de conteúdo, segundo a compreensão de Moraes (1999). A configuração da amostra pode ser examinada nas Tabelas 1 e 2. 
Tabela 1 - Descrição da amostra em relação à idade e ao sexo

\begin{tabular}{|c|c|c|c|c|c|}
\hline \multicolumn{6}{|c|}{ Grupos por idade } \\
\hline & $18-20$ & $21-30$ & $31-40$ & $41-50$ & $51-60$ \\
\hline Feminino (42) & 2 & 23 & 8 & 7 & 2 \\
\hline Masculino (42) & 6 & 21 & 5 & 7 & 3 \\
\hline Total (84) & 8 & 44 & 13 & 14 & 5 \\
\hline
\end{tabular}

Tabela 2 - Descrição da amostra em relação ao nível de instrução

\begin{tabular}{|lc|c|c|c|c|}
\hline \multicolumn{5}{c|}{ Grupos por nível de instrução } \\
\hline & & ens. fundamental & ens. médio & 3ograu incompleto & 3o grau completo \\
\hline Feminino & $(42)$ & - & 6 & 24 & 12 \\
\hline Masculino & $(42)$ & 4 & 14 & 20 & 4 \\
\hline Total & $(84)$ & 4 & 20 & 44 & 16 \\
\hline
\end{tabular}

Observa-se que a freqüência maior da amostra encontra-se nos sujeitos com faixa etária de 21-30 anos e nível de escolaridade de terceiro grau incompleto.

\section{Instrumentos}

Utilizamos a entrevista tópica para explorar a percepção dos/das motoristas em relação a si mesmos/as e ao outro sexo. Nossas entrevistas possuem dois tópicos, abaixo colocados em forma de perguntas. Estes foram apenas norteadores, com o objetivo de ajudar-nos a estabelecer o diálogo desenvolvido no decorrer da entrevista. Conforme Gomes (1987), nas entrevistas, procuramos manter a informalidade de uma conversa, observando, no entanto, que o roteiro baseado nestas duas perguntas fosse devidamente explorado:

Qual a sua percepção do homem motorista? Qual a sua percepção da mulher motorista?
A ordem dessas perguntas variou de acordo com quem encontramos, isto é, foram flexíveis; se estávamos diante de um motorista, perguntávamos primeiro: qual a sua percepção da mulher motorista? Depois formulávamos a próxima pergunta: qual a sua percepção do homem motorista? E vice-versa com a motorista, por acreditarmos que seja mais fácil se falar de outra pessoa em primeiro lugar.

As entrevistas duraram uma média de 25 minutos e foram realizadas em universidades, locais de trabalho e em domicílio.

Também utilizamos um questionário constituído por quatro questões abertas: 
Considero o homem motorista...

Considero a mulher motorista...

- Enquanto mulher motorista eu sou...

Enquanto homem motorista eu sou..

Tanto a entrevista quanto o questionário tinham como objetivo investigar as percepções de gênero dos/das motoristas a respeito de si mesmos e do outro sexo no âmbito do sistema de trânsito.

\section{Procedimentos}

Tanto a entrevista quanto 0 questionário tinham como objetivo investigar as percepções de gênero dos/das motoristas a respeito de si mesmos e do outro sexo no âmbito do sistema de trânsito.
No procedimento de coleta de dados, após a identificação do/da motorista, ele/ela era abordado/a e, frente à sua concordância em participar, era aplicado o questionário ou a entrevista. Na aplicação do questionário, lia-se a frase para o/a motorista e pedia-se que ele/ela completasse rapidamente, com o que the viesse primeiro à mente, sem se importar com questões formais, como pronúncia, concordância verbal ou complexidade gramatical. Também foi informado que seriam mantidos o anonimato e o sigilo das suas respostas à entrevista ou ao questionário.

Para a análise das respostas dos/das motoristas ao questionário ou a entrevista, adotou-se o modelo de análise de conteúdo, que se baseia numa técnica usada em pesquisas qualitativas e que procura tanto organizar os dados em unidades de significado e categorias como interpretá-los a partir do conteúdo do discurso. É, no dizer de Moraes (1999), "uma metodologia de pesquisa usada para descrever e interpretar o conteúdo de toda classe de documentos e textos"(p.9), visando identificar neles um sentido simbólico, considerando o contexto no qual se inscreve.

Segundo Bardin (1994), a análise de conteúdo possui duas funções que, na prática, podem ou não se dissociar: uma função heurística, na medida em que enriquece a tentativa exploratória, aumentando a propensão à descoberta, e uma função de "administração de provas", em que hipóteses servem de diretrizes no sentido de uma confirmação.

Assim, partimos de alguns questionamentos acerca de como se constrói uma representação social, que estratégias são utilizadas quando se trata da temática da percepção de gênero dos/das motoristas e de como as relações de gênero contribuem, ou não, para tal: procedemos à análise do conteúdo dos questionários e das entrevistas, selecionamos as unidades de sentidos, e, posteriormente, definimos as categorias a partir do material em exame, cujas dimensões foram interpretadas posteriormente.

\section{Apresentação e discussão dos resultados}

A análise do material, escrito individualmente, suscitou questionamentos e considerações acerca de como o/a motorista tem representado o gênero nas relações de trânsito, evidenciando semelhanças e diferenças no discurso de homens e mulheres, mobilizando-nos a desenvolver um trabalho de interpretação com base no referencial histórico-crítico e nos estudos de gênero. A Tabela 3 apresenta as sentenças e os dados de forma integral. 
Tabela 3-A mulher e o homem motoristas e seus significados: sentenças, categorias e freqüência de respostas por categoria

\begin{tabular}{|c|c|c|}
\hline Sentença & Categoria & $\begin{array}{c}\text { Freqüência de respostas } \\
\text { por categoria }\end{array}$ \\
\hline \multirow[t]{9}{*}{ Considero o homem motorista... } & imprudente & 19 \\
\hline & auto-suficiente & 5 \\
\hline & agressivo & 5 \\
\hline & desatento & 3 \\
\hline & irresponsável & 3 \\
\hline & péssimo & 3 \\
\hline & ágil & 2 \\
\hline & bom & 2 \\
\hline & normal & 1 \\
\hline \multirow[t]{8}{*}{ Considero a mulher motorista... } & prudente & 11 \\
\hline & boa & 8 \\
\hline & atenciosa & 7 \\
\hline & insegura & 6 \\
\hline & péssima & 5 \\
\hline & regular & 4 \\
\hline & igual ao homem & 3 \\
\hline & corajosa & 1 \\
\hline \multirow[t]{8}{*}{ Enquanto mulher motorista eu sou... } & prudente & 10 \\
\hline & atenta & 7 \\
\hline & cautelosa & 7 \\
\hline & responsável & 6 \\
\hline & boa & 5 \\
\hline & insegura & 4 \\
\hline & desatenta & 4 \\
\hline & defensiva & 1 \\
\hline \multirow[t]{8}{*}{ Enquanto homem motorista eu sou... } & imprudente & 12 \\
\hline & bom & 10 \\
\hline & prudente & 9 \\
\hline & atencioso & 4 \\
\hline & ótimo & 3 \\
\hline & tranqüilo & 3 \\
\hline & ágil & 2 \\
\hline & nervoso & 1 \\
\hline
\end{tabular}

Os critérios utilizados para a criação desses agrupamentos (categorias) fıram: exaustividade (análise de todas as formas de respostas obtidas), exclusividade (cada categ ria classifica um grupo de respostas) e manutenção (as categorias devem ter o mesmo nível d€: inferência e interpretação das respostas, evitando-se grandes oscilações no contínuo objetividade-subjetividade). 
Neste contexto, os/as motoristas envolvidos/as no estudo representam as relações no trânsito como uma experiência de desigualdade, de diferença entre os gêneros, ancorando suas idéias e sentimentos nos valores culturais de uma sociedade tradicional, mas que também se encontra em acelerado processo de mudanças e transformações no que tange à conduta ética, moral e, particularmente, em seus papéis de gênero.

Concomitantemente às idéias estereotipadas das diferenças de gênero, devemos ressaltar, além disso, que alguns/mas motoristas apresentam posicionamentos de um certo equilíbrio (eqüidade) nas relações entre homens e mulheres.

\section{Categorização}

Há duas outras categorias que se constituíram em quatro narrativas. Estas foram agrupando as percepções das pessoas entrevistadas e entrelaçando-se com o referencial teórico, que serviu de base para a discussão, como veremos a seguir. A Tabela 4 apresenta a sistematização das percepções das pessoas no âmbito do sistema de trânsito.

Tabela 4 - Percepções das pessoas no âmbito do sistema de trânsito em relação ao sexo oposto e a si mesmas

A - Percepções das pessoas no âmbito do sistema de trânsito em relação ao sexo oposto/ questõe de gênero:

O que dizem as mulheres a respeito dos homens motoristas

O que dizem os homens a respeito das mulheres motoristas

B -Percepções das pessoas no âmbito do sistema de trânsito em relação a si mesmas como motoristas de trânsito:

Como as mulheres motoristas se percebem

Como os homens motoristas se percebem

\section{A - Percepções das pessoas no âmbito do sistema de trânsito em relação ao sexo oposto/}

questões de gênero: diz respeito a como as pessoas, no sistema de trânsito, percebem a outra do sexo oposto, acentuando os estereótipos de gênero.

O que dizem as mulheres a respeito dos homens

Cada dia mais, a mulher vem promovendo um movimento de reflexão, questionamento e ressignificação de papéis cristalizados e de funções femininas, inclusive conquistando espaços, obtendo reconhecimentos que levam a uma reestruturação de sua identidade e de seu lugar no 
mundo. Essa situação encontra seus fundamentos numa história de muita luta. Tal movimento revela o quanto a mulher tem transitado com desenvoltura nesses novos tempos, opondo-se a uma submissão e dependência históricas nas quais, constantemente, desempenhou uma função inferior (Almeida, N.D.V., 2002a).

É importante ressaltar que, nas últimas cinco décadas, as mulheres aparecem em número cada vez mais acentuado nos volantes brasileiros. Hoje, a mulher exerce vários papéis e tem várias jornadas a cumprir. O carro ajuda muito e, para ela, não é lazer, e, sim, instrumento de trabalho. Para as mulheres em geral, o comportamento de poder e imprudência representou a forma como é percebido o homem em sua relação social com o trânsito: Os homens, quando estão no trânsito, continuam tendo atitudes de uso do poder (...). Os homens, no trânsito, se acham poderosos (....). Eles causam mais acidentes pela imprudência (...).

Dessa forma, as mulheres desenvolveram um sistema de idéias para explicar suas dificuldades no casamento, no trabalho e no sexo cuja validade depende de se considerar as mulheres como discriminadas ao longo do processo histórico-social. O vínculo estabelecido entre as mulheres não é apenas o de uma poderosa irmandade - tem também caráter pessoal. As mulheres falam e são solidárias entre si. Elas ainda não atingiram todas as suas ambições, como igual representação no Parlamento e nas profissões.

Porém, com várias conquistas obtidas, a maioria das mulheres, bem como a sociedade em geral, não foi capaz de abandonar o antigo modelo de mulher responsável pela casa e pelos/as filhos/as. Desse modo, dois modelos foram acoplados, e a maioria das mulheres passou a buscar excelência no lar e no trabalho fora de casa. Temos, além disso, que, da forma como é organizada a sociedade moderna, nem sempre os direitos políticos, sociais, econômicos e civis beneficiaram igualmente homens e mulheres (Almeida, N.D.V., 2002a).

Refletindo, agora, sobre essa participação das mulheres no trânsito, devemos partir do princípio de que, no Brasil, as estratificações de classes são reflexos de uma conjuntura econômica, mas, acima de tudo, de uma realidade cultural, herança sociohistórica que reforça a submissão da mulher, cuja influência vem sendo propagada de geração em geração. Tem-se conhecimento de que há uma ideologia que difunde um perfil feminino dócil, submisso e obediente, uma mulher dedicada apenas às funções maternas. Essa é uma representação da dominação masculina, que tem sido apresentada como natural principalmente nas relações do trânsito: Eles acham que dirigem melhor que as mulheres (...). O homem é arrogante, devendo ser mais educado com os pedestres (...).

A imagem do sexo feminino ficou estereotipada como pé-duro, mas o que observamos no trânsito contradiz essa idéia. Infelizmente, nossa cultura leva a pensar que as mulheres são barbeiras no trânsito (...). Por outro lado, as mulheres percebem ainda os homens como: Eles metem o carro, a gente tem que desviar (...) É agressivo, intransigente, e não respeita as leis para se auto-afirmar como machões (...).

Isso vem demonstrar que, depois de quase seis décadas de feminismo, o homem é revelado na figura de um opressor que impediu a ascensão da mulher no espaço público e limitou sua entrada no mundo às fronteiras da cena doméstica. Simone de Beauvoir (1980) comenta que os verdadeiros opressores das mulheres são o capitalismo e a burguesia, o que se estende aos homens. Essa imagem de opressão de um gênero sobre outro vem, gradativamente, perdendo espaço e sendo
É importante ressaltar que, nas últimas cinco décadas, as mulheres aparecem em número cada vez mais acentuado nos volantes brasileiros. Hoje, a mulher exerce vários papéis e tem várias jornadas a cumprir. O carro ajuda muito e, para ela, não é lazer, e, sim, instrumento de trabalho.
As palavras e as frases em itálico indicam a fala ou a transcrição literal retirada das entrevistas e dos questionários daqui por diante. 
substituída por uma reflexão também sobre a condição de vida dos homens (Connell, 1995; Nolasco, 1995, 1997; Tolson, 1977).

\section{O que dizem os homens a respeito das mulheres}

"Homens e mulheres são iguais em direitos e obrigações". O enunciado constitui o fulcro do inciso I do artigo $5^{\circ}$ da Constituição Brasileira (1988); assim, as mulheres passaram a ter os mesmos direitos dos maridos. Antes, só o homem era considerado cabeça do casal. Agora, a chefia familiar é co-partilhada pelos cônjuges, sem que o homem seja mais importante que a mulher ou vice-versa. Também constatamos que só hoje, já no século XXI, a Câmara dos Deputados aprovou o novo texto do Código Civil, que acaba com a possibilidade de anulação do casamento por perda da virgindade da mulher antes do matrimônio. Em termos puramente jurídicos, são, hoje, mínimas as diferenças no tratamento que a lei dá aos homens e mulheres. Na prática, porém, a tão festejada igualdade entre os gêneros permanece infelizmente - meta ainda distante. Já nas relações de trânsito aqui abordadas, os homens disseram que as mulheres são mais atenciosas quando estão no volante: A mulher motorista é mais atenciosa (...). Ela é mais atenciosa e mais disciplinada em relação ao homem motorista (...). Dirigem com mais atenção e precaução (...).

Os homens falam da dificuldade em incorporar a mudança do papel social da mulher, mudança que busca realizar, em nível das relações de trânsito, a igualdade entre um e outro indivíduo. Essa igualdade destitui o valor dado às diferenças observadas entre os gêneros e que estabelecia a preeminência de um sobre o outro. Dessa forma, pressionados pelo movimento de emancipação feminina a reavaliar suas funções na sociedade e a adotar uma postura mais igualitária, com alterações no que se costumou identificar rigidamente como "papel masculino", os homens vêm reagindo a essas pressões de forma curiosa: aceitando a necessidade de se adequar à nova realidade no campo das atitudes e do comportamento. Embora os homens, de modo geral, achem que têm mais facilidade em manobrar o automóvel, as mulheres, para eles: (...) têm mais cautela, mais visão do perigo que pode ocorrer no trânsito, sobretudo da velocidade e sinalização que ajudam a evitar tais acidentes (...).

Tudo indica que as mulheres (Duarte, 2000) são mais sociáveis e têm mais facilidade de lidar com as emoções no trânsito, enquanto o homem, que é educado para ser mais competitivo, acabaria refletindo esse comportamento no trânsito. As mulheres com comportamento menos agressivo no trânsito e maior tendência a obedecer a leis e regras acabam envolvendo-se em menor número de acidentes sérios: $O$ medo de acidentes faz com que as mulheres sigam mais à risca as regras de trânsito (...). O homem é o que "costura" mais, "fura-filas" e "breca" em cima, elas são mais cuidadosas com o trânsito e calculistas na hora de dirigir (...).

Quando dizemos que os homens são competitivos e as mulheres sociáveis no trânsito, estamos exteriorizando um comportamento que é reflexo de nossa história social e familiar, e, muitas vezes, fica difícil romper essas barreiras históricas, pois essa diferença homem-mulher é introjetada em nossa sociedade. Dessa forma, fica claro que não cabe discutir quem é melhor no trânsito, mas criar um ambiente em que haja espaço para que todas as diferenças sejam respeitadas.

Alguns homens brasileiros (Nolasco, 1995) começam a repensar como constroem seus vínculos afetivos e de trabalho fora do crivo do estereótipo social para eles definidos. Estão buscando encontrar formas próprias para suas 
vidas, estendendo-se além dos paradigmas impostos pelo patriarcado que separa a "vida de um homem" da "vida do macho". Dessa forma, almejam entender as razões que os levaram a ter um padrão de comportamento a que obedecem sem refletir.

\section{do mesmo sexo. \\ Como as mulheres se percebem}

B - Percepções das pessoas no âmbito do sistema de trânsito em relação a si mesmas: diz respeito a como as pessoas se percebem, incluindo a si mesmas e as pessoas

Observamos mudanças recentes ocorridas na sociedade brasileira pela ótica dos interesses da mulher. Para um número maior de mulheres, a condição feminina é mais confortável e, do ponto de vista profissional e pessoal, muito mais gratificante hoje que em qualquer outro período da história. Primeiro, porque elas, finalmente, vêem suas qualidades intelectuais serem apreciadas pela sociedade sem os preconceitos do passado. Nos países ricos e de tradição liberal, as mulheres ocupam mais cadeiras nas universidades e inúmeros cargos de gerência e diretoria. Começam, também, a aparecer no topo da pirâmide empresarial. No Brasil, as mulheres já são maioria no mercado de trabalho e nas salas de aula.

É claro que isso não quer dizer que homens e mulheres tenham empatado em todas as áreas. A dispersão feminina, além das fronteiras das mesas de secretária, das lousas das salas de aula, ainda é muito recente. Elas estudam mais, sentem-se desafiadas a comprovar sua competência.

Dirigir bem não tem a ver com o sexo, e, sim, com a desenvoltura e a tranqüilidade de cada um (...). Alguns estudiosos tentam explicar as diferenças entre homens e mulheres no trânsito da seguinte forma:
"O homem, especialmente o jovem, é mais agressivo, faz manobras mais arriscadas. Já as mulheres são mais prudentes, correm menos, sabem esperar para entrar com segurança numa via. Também interferem, aí, os comportamentos culturais. O homem é educado desde criança para pegar em máquinas; a mulher, para cuidar da casa. São espaços de atuação que exigem atitudes diversas"(Duarte, 2000, p.32).

Ou seja, a menina vai ajudar a mãe na cozinha; o menino vai lavar o carro. Aos 18, o garoto já sabe dirigir, a garota entra para o Centro de Formação de Condutores. Sendo assim, elas mesmas acreditam que, no trânsito, sejam mais cautelosas e responsáveis do que os homens, ou, como elas próprias se definem: (...) as mulheres são mais responsáveis e cautelosas (...). Mais cautelosas, menos imprudentes no trânsito (...). A mulher, no trânsito, usa de prudência (...).

A vida da mulher no trânsito é um paraíso? Ainda não. Constatamos a persistência de algum preconceito que, muitas vezes, dificulta as suas relações no âmbito do sistema de trânsito, embora a mulher venha provando que pratica a direção defensiva (dirigir contando com os erros que os outros eventualmente podem cometer), o que é recomendado em todo o mundo; assim, temos que elas se consideram motoristas que respeitam as normas, diferentemente dos homens, que se envolvem mais em acidentes: Gosto de seguir as leis, o respeito às normas é fundamental para a formação do cidadão, por isso, é difícil cometer uma infração de trânsito (...). O número de acidentes é maior com os homens (...).

Por outro lado, observamos que, entre elas, existem certas contradições por acreditarem também que as mulheres tornam a convivência no trânsito mais lenta e vagarosa: (...) torna o trânsito mais lento (...). É mais vagarosa (...) pecam por excesso de coerência (...). São 
pouco amigas, se acham as donas da rua, mas, de modo geral, provocam menos acidentes.

Porém, o mais importante de tudo isso é que não se pode negar que são muitas as conquistas no campo das relações de gênero. Podemos observar transformações consistentes no âmbito dos direitos, que possibilitaram relações mais igualitárias entre homens e mulheres, principalmente no campo profissional. Muito ainda se precisa avançar, mas já se caminhou consideravelmente, graças, principalmente, ao movimento feminista. No entanto, se essa realidade permite que a mulher se realize no espaço público, percebemos, no dia a dia, que são muitas as dificuldades em conciliar compromissos profissionais e obrigações domésticas.

\section{Como os homens se percebem}

O conceito de masculinidade ou de virilidade, em nossa cultura, ancora-se em sentimentos, atitudes, cognições e padrões comportamentais fixados de longa data em torno do poder e da responsabilidade econômica e política da sociedade. Expectativas solidamente incorporadas cultural e historicamente valorizam, nos homens, a instrumentalidade em detrimento da expressividade, que seria tipicamente feminina.

Ou seja, estereótipos profundamente arraigados, e ainda, em parte, reforçados por símbolos, modelos de carros, códigos de etiqueta social, estilos de auto-apresentação, padrões de comportamento sexual e regras para interação social, embasados pela mídia, cinema e televisão, não vêm permitindo que o homem acompanhe a forma e a velocidade esperadas quanto às novas demandas resultantes do reequilíbrio de poder entre os gêneros: (...) Uma vez que este traz consigo o pensamento de que é muito bom, que não erra, que sabe tudo e nunca vai acontecer algo, que pode correr o bastante porque ele é homem e sabe o que faz.

Homens são seguros, decididos, fortes, corajosos. São frios, auto-suficientes, agressivos. Homens sustentam a família. Só pensam em sexo. Não têm sentimentos. Homens não choram. Não há nada de novo nesses conceitos. O estereótipo do macho talvez exista desde que a humanidade começou a andar ereta e nossos ancestrais do sexo masculino tiveram de esquecer o medo para disputar comida com as feras. Com o tempo, outros adjetivos foram incorporandose a esse leque de caracterizações. Mais recentemente, com os novos conceitos introduzidos pela globalização, cresceu a fama que já tinham de serem ferozmente competitivos no trabalho e, por que não, também nas suas relações sociais no trânsito.

Por qualquer ângulo em que se veja a figura masculina, ela continua associada à força e ao poder. Durante muito tempo, acreditou-se que o homem levava uma grande vantagem por ser a fortaleza que costuma parecer. Estudos recentes, contudo, mostram que a obrigação de se enquadrar nessa imagem de super-herói tem sido, na verdade, a grande fonte de angústia masculina (Almeida, N.D.V., 2002c).

Não se trata de uma crise dos tempos modernos. O fardo de onipotência vem sendo carregado pelos homens através dos séculos embora o aumento da competitividade tenha agravado o problema. O que há de verdadeiramente novo nessa história é que a angústia do macho tem sido cada vez mais analisada e encarada como uma questão de saúde pública.

A cada dia, surgem estudos alertando para a deterioração psíquica masculina, uma dor que pode ser traduzida em números. O sexo masculino lidera as estatísticas mundiais de suicídio, de mortes violentas, de envolvimento 
com álcool. De cada quatro dependentes de drogas em todo o mundo, três são homens. Homens que não sentem medo não são capazes de dosar o grau de risco da situação. Acabam envolvendo-se em negócios desastrosos ou em terríveis acidentes (Almeida, N.D.V., 2002d). Para se ter uma idéia, os dados do Departamento Nacional de Trânsito - DENATRAN (2002) revelam que, em 1999, dos 5.223 acidentes fatais ocorridos nas capitais brasileiras, 4.250 foram com homens: (...) O homem só se dá conta do perigo quando sofre um acidente, o que leva a refletir sobre a importância de ser prudente no trânsito (...). Todo motorista homem, exceto raros, tem a convicção de que só ele é o certo, e que sempre está com a razão (...).

Por um lado, a mídia impõe um meio de o indivíduo conseguir ser um super-homem através de um último modelo de carro importado. Jamais vimos ou assistimos uma propaganda de carro numa favela, na periferia; sempre a cena associa o carro a iate, casa de campo, uma paisagem bonita e conhecida da Europa. As imagens mostram homens e mulheres bonitos/as e de bem com a vida. Esses são os valores de consumo veiculados pela mídia: sucesso, beleza, dinheiro e posição social (Almeida, N.D.V., 2002a, 2002b). Então, o homem comum, independentemente da sua personalidade, da vivência, do desenvolvimento psicológico, entra no carro novo e sente-se o Batman ou o Coringa. Dependendo da sua adequação ou não à sociedade, o carro traz e fomenta esse poder. O homem pega o carro e transforma-se em super-homem, usando o sistema de trânsito como um ambiente de competição ou, como afirmam os próprios sujeitos: (...) O respeito ao pedestre e as ordens de trânsito são, para alguns, apenas obrigações dos outros (...). O homem é relaxado no volante, deixa de lado detalhes que devem ser executados ao dirigir (...). Afobado no trânsito, mais atento (...).
Por outro lado, se a dominação masculina se impôs pelo poder, como ressalta Foucault (1985) ao afirmar que a masculinidade é um "fenômeno do nível discursivo e do discurso enquanto prática", somos levados a pensar não numa masculinidade (evidente, baseada na diferença biológica), mas em masculinidades que, para serem entendidas, devem levar em conta "os contextos e os critérios segundo os quais os homens são diferenciados uns dos outros" (Foucault, 1985, p.79). Segundo a orientação de Connell (1995), podemos pensar que o padrão geral da masculinidade seria a masculinidade hegemônica, a partir da qual (sendo buscada, questionada ou negada) as outras masculinidades, as masculinidades subordinadas, se constituiriam: "A masculinidade hegemônica é um modelo cultural ideal que, não sendo atingível (...) por nenhum homem, exerce sobre todos os homens, sobre as mulheres, um efeito controlador" (Almeida, M. V., 1995, p.163). Tolson, em uma de suas passagens sobre a libertação masculina, comenta:

"Como homens, sentíamo-nos encurralados em nossa própria exclusão - não por sermos excluídos das atividades das mulheres, mas porque, para nós, não havia uma "libertação" equivalente à delas. Uns com os outros, só poderíamos cair na "camaradagem" tradicional, dos bares, com palmadinhas nas costas destinadas a recalcar pelo menos tanto como expressavam. Era impossível falarmos, entre os homens, de sentimentos pessoais de fragilidade ou ciúme. Uma máscara de silêncio masculina dissimulava o vazio da nossa vida" (Tolson, 1977, p.12).

\section{Considerações finais}

A realização deste trabalho possibilitou às estudantes que estão iniciando o seu processo de formação em Psicologia a vivência de um aprendizado dinâmico. As estudantes, ao explorarem as concepções que os/as motoristas 
possuíam acerca dos papéis de gênero, desenvolveram constantes discussões e trocas a respeito das diferentes percepções sobre o gênero bem como uma integração/confronto com os conceitos teóricos.

Temos, então, que, diante do que foi apresentado, objetivamos pesquisar o gênero e as percepções dos/das motoristas no âmbito do sistema de trânsito. Verificamos que a fala dos homens desvela estereótipos sexistas e discriminatórios às mulheres em que as heranças culturais transmitidas pela sociedade (família, amigos/as, professores/as) procuram divulgar a existência de crenças quando o assunto é as diferenças de gênero, levando à permanência de estereótipos ao nível do senso comum.

Nesse sentido, ao analisarmos os estereótipos de gênero nas relações de trânsito, descobrimos a impossibilidade da diferença e da circulação imposta pela força do estereótipo que impede a liberação do significante, isto é, o aprisionamento que impede ou imobiliza o questionamento e a liberdade de escolha. No dizer de Louro (1987), é fundamental estar atento às formas como se produzem as desigualdades entre pessoas e grupos - sejam elas atribuídas à raça, à classe ou ao sexo.

Considerando, ainda, os conteúdos da pesquisa sobre as relações de gênero no trânsito e fazendo uma análise dos dados, constatouse, também, que, em alguns momentos, os trechos da fala dos motoristas foram contraditórios. Às vezes, um aspecto era entendido como pertinente apenas aos homens, ao mesmo tempo em que algum motorista acreditava ser esse pertencente às características individuais - o que gerava dúvida no discurso, confirmando que o objetivo não é o consenso, mas, sim, o levantamento de dúvidas e questões pertinentes. Ficou claro que os homens motoristas vêem as mulheres motoristas como: (...) prudentes, atenciosas (...) inseguras e péssimas (...). Contudo, tanto homens como mulheres podem, ou não, ser bons, educados e firmes em relação ao comportamento no trânsito, constatando que algumas características independem dos papéis culturais e das relações de gênero.

Ao compararmos a fala dos homens a respeito das mulheres e a delas próprias, percebemos que existe uma falta de comunicação entre os homens e as mulheres motoristas. Os homens parecem não entender, ou conhecer, as necessidades das mulheres. Eles têm idéias que coincidem com as delas, mas, no geral, não sabem os motivos de as mulheres encararem de uma outra forma o comportamento no trânsito.

Concluímos, também, que, em alguns momentos, a fala das mulheres a respeito dos homens se assemelha e se aproxima da sua própria percepção a respeito de si mesmos. Podemos observar as diferenças entre homens e mulheres, já que o trânsito não é unissex. Constatamos, outrossim, diferenças significativas nos papéis sociais na forma como homens e mulheres motoristas encaram as suas relações no trânsito; logo, essa fase não é uma experiência homogênea, pois não é possível se estudar o trânsito sem discutir as questões de gênero, sem destacar o nível de instrução e o nível socio-econômico, fatores que influem no modo de perceber a realidade.

Assim, pretende-se dar continuidade à investigação realizada explorando novas perspectivas dos dados aqui obtidos, tendo presente, também, que o tema não se esgota, nem é essa a nossa pretensão; pelo contrário, o tema abre possibilidades de novas leituras, o que nos incita a curiosidade e o desejo de, posteriormente, desenvolver novas reflexões em que o tempo presente exige considerar o objeto da Psicologia inserido historicamente na interface entre o espaço público (em especial no trânsito) e o privado para a construção do bem-estar e da qualidade de vida de homens e mulheres. Tal perspectiva implica um trabalho comprometido com o estudo das cidades e seu planejamento urbano, a saúde pública, o convívio humano, a diversidade e a diferença. 
ALAMEIDA, M. V. Gênero, Masculinidade e Poder. Anuário Antropológico. Rio de Janeiro: Tempo Brasileiro, 1995.

ALMEIDA, N.D.V. A Identidade Masculina e o Movimento de Emancipação da Mulher. Dissertação de mestrado não publicada. Mestrado Interinstitucional em Psicologia Social e da Personalidade. Pontifícia Universidade Católica, Rio Grande de Sul, e Faculdade Frassinetti do Recife, Pernambuco, 2002a.

A Mídia e as Relações de Gênero: Trânsito em Pauta. In M. N. Strey. (org.) Gênero e Questões Culturais: a Vida de Mulheres e Homens na Cultura. Recife: Ed. Universitária UFPE, 2002b, pp.91-106.

Masculinidade e as Relações de Gênero. Arquivos Brasileiros de Psicologia, 54(1), 2002c, pp. 79-92.

Contemporaneidade X Trânsito: Reflexão Psicossocial do Trabalho dos Motoristas de Coletivo Urbano. Psicologia Ciência e Profissão, 22(3), 2002d , pp. 62-69.

Circulação Humana e Subjetividade. In A. C. R. Tupinambá. (org.) Estudos de Psicologia do Trânsito. Fortaleza: Expressão Gráfica, 2002e.

BARDIN, L. Análise de Conteúdo. (L. Reto e A. Pinheiro, trad.) Lisboa: Edições 70 (1977) 1994.

BEAUVOIR, S. O Segundo Sexo, ( $3^{\text {a }}$ ed.). Vol. II. A Experiência Vivida. Rio de Janeiro: Nova Fronteira, 1980.

CONSELHO FEDERAL DE PSICOLOGIA. Caderno de Psicologia de Trânsito e Compromisso Social. Brasília-DF, 2000.

CONSTITUIÇÃO DA REPÚBLICA FEDERATIVA DO BRASIL. São Paulo: Saraiva, 1988.

CONNELL, R. W. Políticas da Masculinidade. Educação e Realidade, 20(2), 1995, pp. 185-206.

DEPARTAMENTO ESTADUAL DE TRÂNSITO DE PERNAMBUCO.

\section{Nemésio Dario Vieira de Almeida}

sicólogo, Especialista em Psicologia Clínica pela UNICAP-PE. Mestre em Psicologia Social Psicologia do Trânsito, desde 1994, no Departamento de Psicologia do DETRAN-PE. Estuda

Cognitiva pela UFPE-PE.

Ana Karina B. de Lima, Consuelo M. Albuquerque \& Luciana Antunes

Rua Adônis de Souza, 26 Quadra 19-Pina - 51110-210 -Recife-PE Telefones: (81) 34548145 / 34673190 / Fax (81) 34548142

E-mail: nemesiodario@hotmail.com

Estatística de Trânsito. Pernambuco: DETRAN-PE, 2002. [http:// www.detran.pe.gov.br/estatística.htm ].

DEPARTAMENTO NACIONAL DE TRÂNSITO. Acidentes de Trânsito: Série Histórica. Brasília: DENATRAN, 2002. [http:// www.detrans.com.br].

DUARTE, D. O Comportamento no Trânsito. Trânsito. Revista da Associação Brasileira dos Departamentos de Trânsito ABDETRAN, 3(7), 2000, pp. 30-33.

FOUCAULT, M. História da Sexualidade. Vol. I. A Vontade de Saber. (7a ed.). Rio de Janeiro: Graal, 1985.

GOMES, W. B. As Aplicações Sociais da Pesquisa Qualitativa. Psicologia: Reflexão e Crítica, 2(1/2), 1987, pp. 3-14.

LOURO, G. L. Prendas e Antiprendas: uma Escola de Mulheres. Porto Alegre: Editora da Universidade-UFRS, 1987.

MORAES, R. Análise de Conteúdo. Educação, XXII (37). Porto Alegre: PUCRS, 1999, pp.7-32.

NOLASCO, S. O Mito da Masculinidade. Rio de Janeiro: Rocco, 1995.

Um "Homem de Verdade". In D. Caldas (org.). Homens. Comportamento, Sexualidade e Educação. São Paulo: Senac, 1997, pp.19-28.

SCOTT, J. Gênero: uma Categoria Útil de Análise Histórica. Educação e Realidade, 15(2), Rio de Janeiro, 1995, pp. 71-99.

STREY, M. N. La Construcción del Proyecto Profesional en la Mujer - Estudio de algunos Aspectos Pscicosociales. Tese de doutorado. Departamento de Psicologia Social e Metodologia, Universidade Autônoma de Madrid, Espanha, 1994.

TOLSON, A. Os Limites da Masculinidade. Lisboa: Assírio \& Alvino, 1977. 